\title{
The effects of prenatal niacin and riboflavin deficiencies in pregnant rats on the learning ability of the offspring'
}

EDWIN I. MEGARGEE AND LORENE L. ROGERS

UNIVERSITY OF TEXAS

Pregnant rats from a heterogeneous strain were assigned to niacin-deficient, riboflavin-deficient or normal diet conditions. Pups were given a normal diet postnatally and their Hebb-Williams Maze performance compared at maturity. Offspring of the niacin-deficient dams made significantly more errors than the controls and there was a similar trend for the riboflavin-deficient Ss.

Postnatal vitamin deficiencies are known to have significant behavioral effects, while prenatal nutritional deficits can cause a variety of physiological abnormalities. However, little research has been reported on the effects of prenatal vitamin deficits on the behavior of offspring. In one of the few such investigations, Scarpelli (1959) tested rats from thiamine-deficient and normal dams for learning ability and found no significant differences. Harrell, Woodyard, \& Gates (1955) found three-year-old Virginia children whose mothers had received vitamin supplements during pregnancy and lactation had significantly higher IQS than a control group whose mothers had received a placebo. Harrell et al were unable to replicate this finding in a Kentucky sample which had a better basic diet.

The purpose of the present study was to test the possibility that prenatal riboflavin or niacin deficiencies would lead to impaired learning ability and to identify methodological problems which might be of importance in such research.

Method

Female Wistar rats mated to male Wistars were randomly assigned to niacin-deficient, riboflavin-deficient or normal diet conditions. Six dams in the niacin-deficient group were injected with $4 \mathrm{mg} / \mathrm{kg}$ of 6-aminonicotinamide, a biochemical niacin antagonist, on days 9 and 11 of gestation. Five of these animals resorbed all the fetuses, and one had a litter of nine, of which three died. Three dams injected with $2 \mathrm{mg} / \mathrm{kg}$ of the niacin antagonist delivered litters of two to four. Of these 10 pups, three died. (Litter size was probably reduced by maternal cannibalism.) All the dams injected with the niacin antagonist were fed the normal diet of ground Purina lab chow ad lib throughout gestation and lactation, and the pups had a normal diet at all times.

Two dams were fed a riboflavin-deficient diet prepared by the Nutritional Biochemical Corporation beginning the day pregnancy was confirmed and con- tinuing until the day before delivery, at which time the normal diet was reinstated. One dam had a litter of 13 , of which 10 died, and the second a litter of 10 , all of which survived.

The five control dams, fed the normal diet ad lib throughout gestation and lactation, had litters of nine to 16 pups with an observed $16.7 \%$ postnatal mortality rate; at weaning 46 of the pups were randomly selected and reared to maturity.

At age 90-110 days, the animals were tested on the Hebb-Williams Maze using the procedures outlined by Rabinovitch \& Rosvold (1951). After preliminary maze adaptation, a series of six practice problems were used until each animal had attained a minimum criterion of nine runs in $60 \mathrm{sec}$. on two consecutive sessions. The learning measure consisted of the total number of errors in eight runs to each of 12 different test problems.

Resulis

Litter size, birth weight and mortality data are presented in Table 1 . The niacin-deficient group had considerably smaller litters, and both riboflavin and niacin deficiencies were associated with higher postnatal mortality.

The 46 control animals had a median of 162.5 errors, with a range of 99 to 277; the 13 pups from riboflavindeficient dams had a median of 183.5 errors, with a range of 117 to 224; and the 13 pups from niacindeficient dams had a median of 208.5 errors, with a range of 119 to 253 . The distribution of error scores for the three groups is indicated in Fig. 1.

Table 1.

The Effect of Diet on Litter Size, Mortality and Birth Weight

\begin{tabular}{|c|c|c|c|c|c|}
\hline $\begin{array}{l}\text { Condition } \\
\text { During } \\
\text { Gestation }\end{array}$ & $\begin{array}{l}\text { No. of } \\
\text { Dams }\end{array}$ & $\begin{array}{c}\text { Median Litter } \\
\text { Size }\end{array}$ & $\begin{array}{c}\text { Range of } \\
\text { Litter Size }\end{array}$ & $\begin{array}{l}\text { Postnatal } \\
\text { Mortality } \\
\text { Rate }\end{array}$ & $\begin{array}{c}\bar{x} \text { Birth } \\
\text { Weight }(g m)\end{array}$ \\
\hline Normal Diet & 5 & 12 & $9-16$ & $16.7 \%$ & 5.81 \\
\hline \multicolumn{6}{|l|}{ Riboflavin } \\
\hline $\begin{array}{l}\text { Deficient } \\
\text { Diet }\end{array}$ & 2 & 11.5 & $10-13$ & $43.5 \%$ & 4.07 \\
\hline \multicolumn{6}{|l|}{ Niacin } \\
\hline $\begin{array}{l}\text { Antagonist } \\
(4 \mathrm{mg} / \mathrm{kg})\end{array}$ & 6 & 0 & $0-9$ & $33.3 \%$ & 6.30 \\
\hline \multicolumn{6}{|l|}{ Niacin } \\
\hline $\begin{array}{l}\text { Antagonist } \\
(2 \mathrm{mg} / \mathrm{kg})\end{array}$ & 3 & 4 & $2-4$ & $30.0 \%$ & 6.20 \\
\hline
\end{tabular}




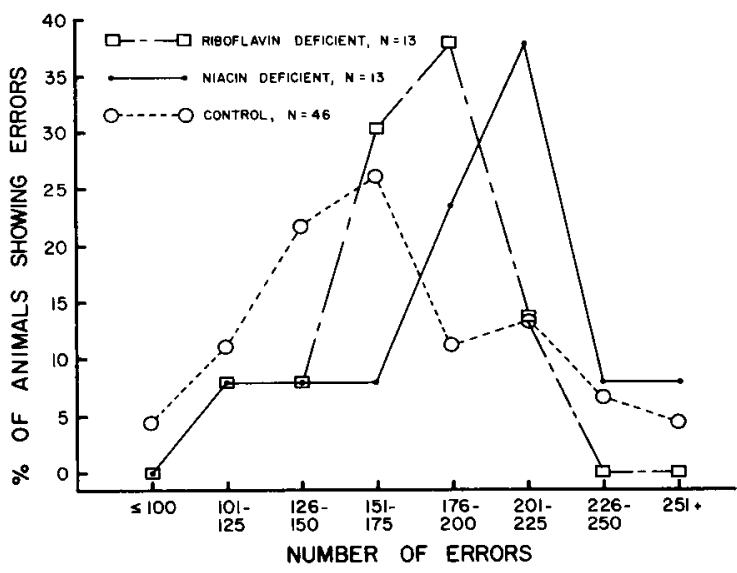

Fig. 1. Distribution of errors for Hebb-Williams Maze performance for offspring of niacin-deficient, riboflavin-deficient and normal dams.

Mann-Whitney $U$ tests showed that the niacin-deficient group made significantly more errors than the controls $(p=.02$, one tail) and that the riboflavindeficient animals showed a similar, nonsignificant, trend $(p=.09$, one tail).

\section{Discussion}

The results of this study indicate that the prenatal niacin and riboflavin deficiencies probably adversely affected the learning ability of the offspring as measured by the Hebb-Williams Maze. The fact that all deficient animals obtained scores falling within the control range suggests that these effects are not profound or that they are complexly regulated.

While the results of this study were in the predicted direction, further research is necessary to determine the degree of prenatal dietary influence. The differences observed could have been genetically determined, although the random assignment of dams to various conditions made systematic genetic differences unlikely. Any such genetic differences would be minimized by use of homozygous animals. The possibility also exists that an adequate nutritional balance may not have been restored in all dams during lactation. If so, the experimental animals might have had a less adequate postnatal diet. Foster-rearing of offspring would control for this contingency. Finally, experimenter bias cannot be ruled out, as the $E$ was aware of the group designation of seven riboflavindeficient and 15 control animals.

Despite these methodological problems, the results of this study are sufficiently encouraging to warrant further research on the behavioral consequences of prenatal nutritional deficiencies. Variables to be investigated include the effects of other nutrients, of withholding nutrients at different times during gestation and the effects of prenatal deprivation on other behavioral dimensions such as activity, stamina and emotionality.

\section{References}

Harrell, Ruth, Woodyard, Ella, \& Gates, A. I. The effects of mothers' diets on the intelligence of the offspring. New York: Bureau of Publications, Teacher's College, Columbia University, 1955.

Rabinovitch, M. S., \& Rosvold, H. E. A closed-field intelligence test for rats. Canad. J. Psychol., 1951, 5, 122-128.

Scarpelli, E. Maternal nutritional deficiency and intelligence of the offspring (thiamine and iron). J. comp. physiol. Psychol., $1959,52,536-539$.

\section{Note}

1. The present study was supported in part by Grant VRA-RT-12 from the Office of the Vocational Rehabilitation Administration, Department of Health, Education, and Welfare, Washington, D. C. The investigators are grateful to Claude Robert Cloninger, Joan V. Moore and Rebbecca I. Muecke for their assistance and to Delbert Thiessen for critically reading an earlier draft of this report. 